\title{
38 \\ PEKERJA SOSIAL DAN PENDIDIKAN INKLUSI
}

\author{
Oleh: \\ Nurul Fadhilah Rezeki, \& Binahayati Rusydi \\ Email: \\ (nurulfadhilahr@gmail.com; titi.rusyidi06@gmail.com)
}

\begin{abstract}
ABSTRAK
Pendidikan merupakan hak bagi setiap orang, termasuk bagi anak dengan disabilitas. Indonesia dengan beribu pulau yang dimilikinya sampai saat ini belum merata pembangunannya, termasuk di dalamnya akses terhadap pendidikan. Data yang diperoleh dari buku Profil Anak Indonesia 2013 menyebutkan bahwa sebanyak 35,25\% anak dengan disabilitas belum/tidak pernah sekolah, 43,13\% tidak/belum tamat SD. Menurut Rustanto (2013), pekerja sosial sekolah merespon perwujudan hak semua anak untuk mendapatkan pendidikan termasuk bagi anak yang memiliki kebutuhan khusus serta keluarganya. Dalam pelaksanaan pendidikan inklusi, pekerja sosial sekolah memiliki peranan menjadi jembatan bagi anak dengan disabilitas, masyarakat, keluarga, dan pemerintah. Profesi pekerja sosial professional yang masih berkembang di Indonesia menjadi salah satu hambatannya. Tidak banyak orang yang mengetahui apa itu pekerja sosial professional membuat urgensi pekerja sosial di berbagai setting tidak begitu tampak. Hal yang sama terjadi bagi para pekerja sosial sekolah. Pentingnya peran pekerja sosial di sekolah tidak tampak karena hingga saat ini hanya sedikit sekolah yang memiliki pekerja sosial dan banyak sekolah yang tetap melaksanakan "inklusi"-nya tanpa keberadaan pekerja sosial. Sebenarnya dengan melihat begitu pentingnya peran pekerja sosial di sekolah, pelaksanaan pendidikan inklusi akan lebih maksimal dan mengakomodir kebutuhan dan hak para siswa.
\end{abstract}

Kata-kata kunci: ADD (anak dengan disabilitas), Inklusi, pekerjaan sosial, pendidikan, pekerja sosial sekolah

\section{Pendahuluan}

Pekerjaan sosial merupakan suatu profesi dengan beragam setting yang meliputi berbagai aspek dalam kehidupan manusia. Fokusnya, terutama, pada hak asasi manusia yang dimiliki seseorang. Walaupun masih banyak orang yang menganggap bahwa pekerja sosial bukan merupakan suatu profesi yang professional, melainkan merupakan bagian dari gerakan sosial seperti relawan. Namun, di sisi lain pekerjaan sosial merupakan suatu profesi yang memiliki poin-poin untuk dapat dikatakan sebagai profesi, seperti kode etik, body of knowledge, dsb. Pekerja sosial, saat ini sudah mulai di kenal dalam perannya di setting-setting tertentu. Sebut saja pekerja sosial sekolah yang saat ini sudah mulai di kenal keberadaannya, walaupun pada kenyataannya masih banyak sekolah yang tidak memiliki pekerja sosial. Salah satu bentuk sekolah yang dianggap sangat perlu memiliki pekerja sosial sebagai bagiannya adalah sekolah inklusi. Hal tersebut menjadi penting mengingat masyarakat Indonesia masih belum bisa dikatakan sebagai masyarakat yang inklusif. Banyak masyarakat yang menganggap bahwa kecacatan fisik, mental, bahkan gangguan belajar sebagai hal yang membuat mereka merasa risih. 
Pelaksanaan pendidikan inklusif tak jarang dianggap sebagai salah satu langkah dan upaya pemerintah dalam mengupayakan dan membentuk masyarakat yang inklusif, masyarakat yang terbuka dengan beragam perbedaan yang dimiliki individu, serta melihat seseorang sebagai manusia seutuhnya yang memiliki beragam keunikannya. Pendidikan juga merupakan upaya untuk memanusiakan manusia dan upaya mengurangi angka/tingkat kemiskinan.Tak jarang mereka yang berkebutuhan khusus/ mengalami disabilitas dianggap sebagai aib keluarga, dikekang dan di batasi gerak sosialnya oleh keluarga. Hal tersebut secara tidak langsung membuat mereka menjadi pengisi angka pengangguran mutlak, padahal mereka yang mengalami disabilitas juga memiliki hak yang sama dengan orang lain dalam mengakses pendidikan dengan mudah. Dengan tidak mengupayakan pendidikan yang dapat mengembangkan potensi mereka, sama saja dengan membiarkan mereka menjadi "beban bagi negara", karena mereka yang sudah masuk usia kerja dan dianggap dapat menyumbang pemasukan bagi negara justru tidak bekerja dan tidak berpenghasilan.

Dalam pelaksanaan pendidikan inklusi anak dengan disabilitas dan anak lainnya belajar di kelas yang sama, untuk itu sekolah secara fasilitas dan cara pegajaran perlu melakukan penyuaian. Orang tua murid lain juga perlu melakukan penyesuaian dalam bentuk mendorong anaknya untuk bergaul dan membatu anak dengan disabilitas dalam proses belajar, tidak memberikan stigma kepada anak dengan disabilitas, mengajak masyarakat khususnya orang tua lain yang belum menerima keberadaan anak dengan disabilitas di sekolah agar tidak menyudutkan anak dengan disabilitas. Murid perlu memahami bahwa diantara mereka terdapat teman-teman yang tidak sama keadaannya dengan dirinya, mereka perlu belajar menerima kekhususan teman-teman dengan disabilitas, membantu mereka dan sebagainya. Tidak hanya sekolah, orang tua murid, dan murid saja yang perlu melakukan penyuaian, tetapi pemerintah juga perlu melakukan hal yang sama dengan mengusahakan infrastruktur dan aksesibilitas yang mendukung anak dengan disabilitas untuk sekolah, membuat peraturan yang mengharuskan sekolah yang menjadi sekolah inklusi untuk mengikuti perdoman pelaksanaan inklusi yang telah ditetapkan agar pelaksanaan pendidikan inklusi yang dilakukannya dapat berjalan dengan optimal. Penyesuaian yang sama juga perlu dilakukan masyarakat dalam upaya mendukung pelaksanaan pendidikan inklusi di daerahnya. Namun, tidak jarang masyarakat sulit dalam menerima kehadiran mereka, oleh karena itu peran pekerja sosial dalam pendidikan inklusi menjadi penting. Pekerja sosial dalam pelaksanaan pendidikan inklusi memiliki beragam peran termasuk di dalamnya menjadi jembatan antara sekolah-masyarakat-orang tua murid-muridpemerintah. Pekerja sosial sekolah berusaha untuk menunculkan/ meningkatkan penerimaan masyarakat terhadap anak dengan disabilitas sehingga pencapaian dari anak dengan disabilitas di sekolah menjadi lebih optimal.

\section{Pendidikan Inklusif}

Pentingnya pendidikan terutama pada anak, sudah diakui secara internasional dan sudah menjadi hak setiap anak untuk memperoleh pendidikan. Tahun 1989 UN General Assembly mengadopsi The Convention on The Rights of the Child yang mengikrarkan "Make primary education compulsory and available free to all" (Ban Ki-Moon, 2007:38). Pernyataan/ ikrar tersebut muncul sebagai langkah awal untuk meningkatkan partisipasi anak dalam pendidikan di sekolah yang saat itu masih rendah karena beragam hal mulai dari gender, budaya, hingga fisik anak. Ikrar tersebut kemudian berkembang menjadi lebih spesifik lagi dalam bentuk ikrar lain. Ikrar mengenai pendidikan inklusif muncul dalam The Salamanca Statement and Framework for Action on Special Needs Education, tahun 1995. Dalam deklarasi ini, 92 negara dan 25 organisasi internasional berkumpul di Salamanca, Spanyol untuk mendukung pencapaian Education for All dengan menyatukan persepsi mengenai anak yang salah satu outputnya adalah menyelenggarakan pendidikan inklusif agar semua anak dapat mengakses pendidikan. Deklarasi ini percaya bahwa setiap anak memiliki hak untuk mendapat pendidikan, memiliki karakteristik khusus/unik dan sistem serta program pendidikan harus disesuaikan untuk mengakomodir kekhususan yang ada. 
Banyak anggapan, bahwa pendidikan inklusif merupakan upaya bentuk penyelenggaraan pendidikan bagi anak berkebutuhan khusus (anak dengan disabilitas) yang dikembangkan pemerintah untuk mengatasi presentase populasi anak berkebutuhan khusus (anak dengan disabilitas) bersekolah yang kecil dan mengupayakan pendidikan untuk semua. Indonesia merupakan salah satu negara yang mendukung pelaksanaan pendidikan inklusi untuk meningkatkan angka partisipasi sekolah bagi semua anak. Bentuk komitmen ini dilakukan dengan menjabarkan landasar filosofis, landasan yuridis, dan mengajak semua stake holder yang terlibat dalam pelaksanaan pendidikan inklusi untuk bersamasama berusaha semaksimal mungkin untuk mencapainya.

Di Indonesia, landasan filosofis dari pendidikan inklusi menurut Suparno dalam Pendidikan Anak Kebutuhan Khusus UNIT 2 adalah

- Pendidikan adalah hak mendasar bagi setiap anak, termasuk anak berkebutuhan khusus

- Anak adalah pribadi yang unik yang memiliki karakteristik, minat, kemampuan dan kebutuhan belajar yang berbeda

- Penyelenggaraan pendidikan menjadi tanggung jawab bersama antara orang tua masyarakat dan pemerintah

- Setiap anak berhak mendapat pendidikan yang layak

- Setiap anak berhak memperoleh akses pendidikan yang ada di lingkungan sekitarnya

Dari pernyataan diatas, tersirat bahwa pendidikan inklusif memiliki tujuan yang beragam, misalnya meningkatkan angka partisipasi ABK yang bersekolah, hingga menciptakan masyarakat yang memandang seseorang bukan dari label (kecatatan) namun sebagai individu seutuhnya yang memiliki keunikan tersendiri. Hal tersebut juga dijelaskan oleh Warner (2006), yang menyatakan bahwa pendidikan inklusif merupakan salah satu upaya dalam menciptakan lingkungan yang inklusif, karena pendidikan inklusif tidak lepas dari kerja sama antara orang tua, pihak sekolah, masyarakat, dan pemerintah. Saat semua pihak terkait sudah dapat melaksanakan pendidikan inklusif dengan baik, dapat dikatakan bahwa penerimaan masyarakat terhadap anak/mereka yang berkebutuhan khusus sudah baik dan tercipta lingkungan yang inklusif. Hal ini menjadi penting karena pendidikan tidak hanya terkait akses, namun proses memberfungsikan anak berkebutuhan khusus untuk menerima hak mereka dan meningkatkan pencapaian prestasi yang akan meningkat seiring meningkatnya penghargaan dan percaya diri. Warner (2006).

Di Indonesia pendidikan inklusi tidak hanya muncul sebagai bentuk mendukung terciptanya Education for All saja, namun juga merupakan upaya untuk memberikan pendidikan bagi mereka yang tinggal di pedesaan. Indonesia dengan beribu pulau yang dimilikinya sampai saat ini belum merata pembangunannya, termasuk di dalamnya akses terhadap pendidikan. Data yang diperoleh dari buku Profil Anak Indonesia 2013 menyebutkan bahwa sebanyak 35,25\% anak dengan disabilitas belum/tidak pernah sekolah, 43,13\% tidak/belum tamat SD. Selain itu, juga di sebutkan bahwa sebanyak $36.66 \%$ anak dengan disabilitas di pedesaan belum/tidak sekolah sedangkan $19.98 \%$ lainnya putus sekolah, dan sisanya sekolah. Mengingat presentase jumlah anak yang tidak sekolah yang masih tinggi pemerintah bersama NGO (Non Government Organization) terkait berusaha untuk mengupayakan pendidikan inklusi di daerah-daerah sehingga anak dengan disabilitas di pedesaan juga mengakses pendidikan. UNESCO 1994 dalam Alimin (2008:7), memberikan gambaran bahwa:

"Pendidikan inklusif berarti bahwa sekolah harus mengakomodasi semua anak, tanpa kecauali ada perbedaaan secara fisik, intelektual, sosial, emosional, bahasa, atau kondisi lain, termasuk anak penyandang cacat dan anak berbakat, anak jalanan, anak yang bekerja, anak dari etnis, budaya, bahasa, minoritas dan kelompok anak-anak yang tidak beruntung dan terpinggirkan. Inilah yang dimaksud dengan one school for all." 
Dari pendapat tersebut tergambarkan bahwa pemerintah memiliki kewajiban untuk memfasilitasi seluruh warga negara untuk mengakses pendidikan sehingga prinsip Education for All akan tercapai, salah satunya melalui one school for all.

\section{Pekerja Sosial Sekolah}

Sebagai pekerja sosial, dengan membahas pendidikan inklusi kita tidak dapat memisahkannya dari konteks hak asasi manusia. Pekerjaan sosial dan hak asasi manusia merupakan dua hal yang tidak dapat dipisahkan. HAM menjadi dasar para pekerja sosial dalam memberikan pelayanan. Menurut Ife (2008), pekerja sosial yang bergerak di bidang HAM akan memiliki banyak peran dalam memperjuangkan hak, mereka bisa berperan sebagai a child protection social worker, a social worker at a women's refuge, pekerja sosial yang dalam tim assessment untuk orang dengan disabilitas, dsb. Diskriminasi merupakan salah satu hal yang di tentang HAM, termasuk didalamnya diskriminasi dalam bidang pendidikan bagi Anak Dengan Disabilitas (ADD).

Dalam membahas mengenai pendidikan inklusi salah satu setting pekerja sosial yang terkait adalah pekerja sosial yang bekerja di sekolah. Pekerja sosial yang berkerja di sekolah dan berusaha untuk memastikan agar setiap anak terjamin pemenuhan hak-nya adalah pekerja sosial sekolah.

Pekerja sosial sekolah adalah salah satu bidang praktek pekerjaan sosial, yang antara lain memberikan pelayanan konseling penyesuaian diri di sekolah (school adjustment counseling), tes kemampuan pendidikan (educational testing), konseling keluarga (family counseling) dan pengelolaan prilaku (behaviour management). Pekerja sosial sekolah juga merespon perwujudan hak - hak semua anak untuk mendapatkan pendidikan termasuk bagi anak - anak yang memiliki kebutuhan khusus (anak penyandang cacat) serta keluarganya. Rustanto (2013)

Berbeda dengan pendapat yang diutarakan Rustanto, Openshaw (2008) menjelaskan bahwa 4 tugas pokok pekerja sosial, adalah :

1. Konsultasi dengan pihak lain dalam sekolah

2. Assessment dalam pelayanan langsung, konsultasi dan pengembangan program

3. Intervensi dengan anak, keluarga dan kelompok

4. Membantu pengembangan program

(diterjemahkan oleh penulis)

Pekerja sosial sekolah memiliki tugas lain selain yang telah diutarakan diatas, yaitu menjadi jembatan antara sekolah-masyarakat-orang tua murid-murid-dinas terkait. Tidak sedikit masyarakat yang merasa risih dengan keberadaan anak dengan disabilitas di sekolah yang berada di lingkungan tempat tinggalnya, ini merupakan salah satu tugas dari pekerja sosial untuk membuat mereka dapat menerima keberadaan anak dengan disabilitas di sekolah, baik itu dengan melakukan FGD, pendekatan personal, dsb. Dalam penyediaan fasilitas sekolah yang ramah bagi anak dengan disabilitas, pekerja sosial dapat mengadvokasi sekolah terhadap dinas terkait. Bagi murid yang memiliki masalah dalam sekolah baik yang berasal dari dalam diri maupun luar diri anak, pekerja sosial pun berusaha untuk meminimalisir baik dengan memberikan pelayanan langsung berupa konsultasi, konseling keluarga, behavior management, dsb.

Peran lain dari pekerja sosial adalah membantu pengembangan program, dalam konteks pendidikan inklusi pekerja sosial dapat membantu untuk mengembangkan program pelayanan/ penyelenggaraan pendidikan inklusi yang dapat mengakomodir kebutuhan dari anak dengan disabilitas dan anak normal di waktu yang bersamaan. Pengakomodiran/ penjaminan hak ini juga merupakan salah satu kewajiban bagi pekerja sosial yang bekerja di sekolah, karena salah satu tugas pekerja sosial sekolah adalah memastikan hak dari anak dari anak dengan disabilitas dari sejak lahir hingga berumur 21 tahun, termasuk keluarganya, terpenuhi seperti yang dinyatakan Openshaw (2008).

\section{Pekerja Sosial dan Pendidikan Inklusi}


Peran pekerja sosial yang penting dalam pelaksanaan pendidikan inklusi di Indonesia sampai saat ini belum berjalan beriringan. Profesi pekerja sosial professional yang masih berkembang di Indonesia menjadi salah satu hambatannya. Tidak banyak orang yang mengetahui apa itu pekerja sosial professional membuat urgensi pekerja sosial di berbagai setting tidak begitu tampak. Hal yang sama terjadi bagi para pekerja sosial sekolah. Pentingnya peran pekerja sosial di sekolah tidak tampak karena hingga saat ini hanya sedikit sekolah yang memiliki pekerja sosial dan banyak sekolah yang tetap melaksanakan "inklusi"-nya tanpa keberadaan pekerja sosial. Sebenarnya dengan melihat begitu pentingnya peran pekerja sosial di sekolah, pelaksanaan pendidikan inklusi akan lebih maksimal dan mengakomodir kebutuhan dan hak para siswa saat pekerja sosial dilibatkan.

\section{Kesimpulan}

Sekolah yang memberikan pelayanan pendidikan inklusi seharusnya memberikan pelayanan pendidikan yang sesuai dengan kekhasan/ kekhususan dari setiap anak, terutama dari ABK. Hal tersebut tampak dari cara dan teknik pengajaran, fasilitas, dan kurikulum yang ada. Salah satu tantangan terbesar yang dihadapi oleh pelayana pendidikan inklusi adalah keterbatasan tenaga pengajar dengan latar belakang pendidikan luar biasa. Dengan tenaga pengajar yang terbatas dan latar belakang pendidikan pengajar yang memiliki latar pelakang dari pendidikan luar biasa, akan berimplikasi pada guru pengajar kelas yang akan kewalahan saat melaksanakan proses belajar mengajar. Mungkin, masalah kemampuan dari para pengajar dalam menghadapi ABK sudah terbantu dengan adanya pelatihan yang diberikan oleh pemerintah. Namun, masalah yang muncul dari ketidakjelasan standarisasi sekolah inklusi tidak hanya sampai disitu.

Mengingat masih banyaknya keterbatasan dalam penyelenggaraan pendidikan inklusi di Indonesia, pekerja sosial memegang salah satu peranan penting dalam memastikan penyelenggaraan pendidikan inklusi ini dapat mengakomodir kebutuhan semua anak termasuk yang berkebutuhan khusus (dengan disabilitas) dan dapat berjalan secara optimal. Sebagai pekerja sosial, peranannya tidak hanya sebatas itu, namun juga membantu agar anak-anak dengan disabilitas dapat mengembangkan dirinya secara optimal baik dari segi sosial maupun akademis. Jadi pelayanan yang diberikan pekerja sosial dalam setting sekolah tidak hanya terbatas pada anak yang bersekolah saja, namun juga pada keluarga, kelompok, masyarkat dan di tingkat regulasi dan perencanaan program.

\section{Saran}

Saran dalam mengoptimalkan pelaksanaan pendidikan inklusi agar dapat mengakomodir hak dari anak dengan disabilitas adalah dengan melibatkan pekerja sosial dalam tim yang terlibat. Tidak menutup kemungkinan juga jika nantinya di Indonesia keberadaan pekerja sosial sekolah menjadi salah satu syarat bagi sekolah untuk mendapat akreditasi "A", sehingga diharapkan setiap sekolah akan berlomba-lomba mempekerjakan pekerja sosial seperti apa yang terjadi pada rumah sakit dengan pekerja sosial medis. Regulasi mengenai siapa saja dan peran dari masing-masing profesi yang terlibat dalam proses assessment anak di sekolah inklusi juga harus diperjelas agar tidak terjadi kesalah pahaman peran (tumpang tindih) pekerjaan. Selain itu lembaga pendidikan yang menyelenggarakan pendidikan profesi yang terkait dengan pendidikan inklusi, seperti perguruan tinggi untuk guru, pekerja sosial, psikolog, dsb., perlu memberikan pemahaman kepada siswanya mengenai bekerja dalam tim yang terdiri dari beragam disiplin ilmu, sehingga dalam prakteknya mereka tidak akan merasa kaget dan canggung saat bekerja dalam tim.

\section{Sumber buku :}

Ife, Jim. 2008. Human Rights and Social Work: Toward Rights-Based Practice. Sidney: Cambridge University Press.

Kementerian Pemberdayaan Perempuan dan Perlindungan Anak, BPS. 2013. Profil Anak Indonesia 2013. Jakarta : PT. Desindo Putra Mandiri. 
Ki-Moon, Ban. 2007. Children and The Millennium Development Goals : Progress towards A World Fit for Children. New York: UNICEF.

Openshaw, Linda. 2008. Social Work in Schools. New York : The Guilford Press

Warner, Helen K. 2006. Meeting the Needs of Children with Disabilities: Families and Professionals Facing The Challenge Together. New York: Routledge.

\section{Sumber Lainnya :}

Anuar, Azad Athahiri dan Rozubi, Norsayyidatina Che.2010. "Keperluan Pendidikan Inklusif dalam Program Pendidikan Arus Perdana di Malaysia". International Conference on Learner Diversity.

Pendidikan Anak Kebutuhan Khusus UNIT 2, Suparno, Edi Purwanto, Hakikat Layanan Bagi Anak Berkebutuhan Khusus.

Alimin, Zaenal. (2008). Pemahaman Konsep Pendidikan Kebutuhan Khusus Dan Anak Berkebutuhan Khusus.(Online). Tersedia: http://zalimin. blogspot.com/2008/03/pemahaman-konseppendidikan-kebutuhan.html. [31/10/14]

Konselor qita. 2014. "PENDIDIKAN INKLUSIF". Melalui http://konselorqita.blogspot.com/2014/01/pendidikan-inklusif.html, [14/03/14]

Rustanto, Bambang. 2013. "Pekerjaan Sosial di Sekolah". Melalui http://bambangrustanto.blogspot.com/2013/08/pekerjaan-sosial-di-sekolah.html, [20/09/14] 